\title{
Assessment and social change Empowering underserved students to reimagine their future through STEM outreach
}

\section{$\mathbf{U}$} sing a STEM conference model is a method for creating social change among underrepresented student populations. Through outreach to local schools, university libraries can help pre-college students gain a better understanding of STEM fields and can ul- lemma," in order for our nation to maintain leadership in STEM fields and competitiveness in the global economy, we must activate the hidden workforce of young men and women who have traditionally been underrepresented in STEM careers. ${ }^{1}$ No source

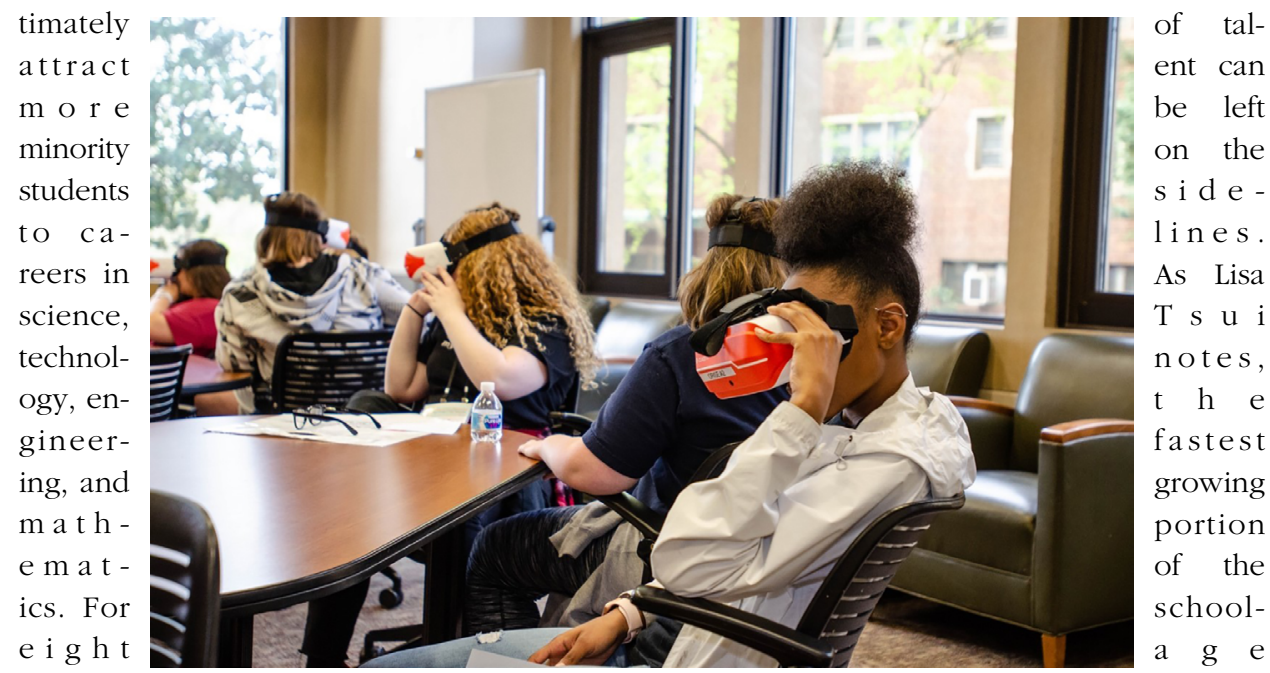

years, Students participating in the workshop "Virtual Reality: An Introduction to poputhe Uni- Total Immersion," presented by members from Oak Ridge National Laboratory. lation versity

is $\mathrm{mi}^{-}$

of Tennessee (UT) Libraries has hosted a STEM conference for local middle and high school students.

\section{Bridging the STEM Gap}

Bridging the gap of minority students in STEM fields is a national challenge for universities. As the National Action Council for Minorities in Engineering points out in their report, "Confronting the 'New' American Di- nority students and they represent a great potential pool of future entrants into STEM fields. ${ }^{2}$
Thura Mack is professor at University of Tennessee Libraries, email: tmack@utk.edu, and Savanna Draper is a graduate student at the University of Tennessee School of Information Science, email: sdraper1@vols.utk.edu

C 2019 Thura Mack and Savanna Draper 
So what can universities and secondary schools do to make STEM fields more attractive to this underrepresented population? One recent assessment of U.S. competitiveness in the global market noted, "National initiatives to increase minority students' presence in [STEM] fields focus on students' motivations and intentions to complete high school and attend college." 3 Academic libraries are the ideal platform to initiate programs that can inspire students to set their sights on college and STEM careers. They have the infrastructure in place to put STEM into a context that is inclusive and inviting. Academic libraries are likely to have technology in place, as well as existing partnerships with STEM organizations Future scientists taking a photo opportunity. and other educators at their institutions that allow them to present STEM topics in the library's welcoming environment. Intentionally creating programs for underserved populations allows students to make informed decisions about opportunities in STEM fields and to imagine themselves in STEM careers.

\section{Big Orange STEM Saturday}

Big Orange STEM Saturday (BOSS) began approximately eight years ago. It started as a daylong symposium and then grew into a mini-conference. Over the years, the conference has grown tremendously, and attendance has nearly tripled in size. The growth can be partially attributed to our partner, the UT's College Access and Persistence Services (CAPS) Outreach Center. The CAPS Outreach Center is a grant-funded program that provides services to help students over- come social, academic, financial, and cultural barriers in higher education. Research has shown that universities face major problems in recruiting and retaining low-income and first-generation students. The CAPS Outreach Center provides services to individuals from disadvantaged backgrounds to prepare them to succeed in postsecondary or professional academic programs, including activities to strengthen the math and science skills of students interested in STEM fields. Working with the CAPS Outreach Center has made it possible for BOSS to reach the desired underserved demographics.

$\mathrm{T}$ h $\mathrm{e}$ BOss conference has three pillars: hands-on workshops, an exhibitor fair, and a keynote facilitator who includes an interactive activity. Every year, the BOSS team releases a call for proposals to handpick eight workshops and one keynote activity. Along with this process, we also reach out to university and community partners to get groups and organizations to take part in the exhibitor fair. We work with the University Libraries' Marketing Department to create promotional materials and programs for the conference. We create a budget to include lunch for all, UT Libraries brand giveaways, and honorarium for a keynote speaker. Another large part of the conference planning logistics is maintaining the BOSS website and registration process.

\section{The student experience}

Presenting STEM information in a conference setting like BOSS allows pre-college students to experience key educational 
trends and to explore college or careers in manageable bits. Students are introduced to a multitude of STEM-related majors and careers at a halfday conference at UT's premier research university. BOSS offers several sessions about various STEM topics, and each student gets to participate in two hands-on sessions based on their STEM tracks and interests.

Throughout this STEM initiative, an effective methodology is put into place to engage and introduce students to skills they will need to develop in order to study STEM. Participants are also introduced to career planning programs and other support systems available to them as new students at

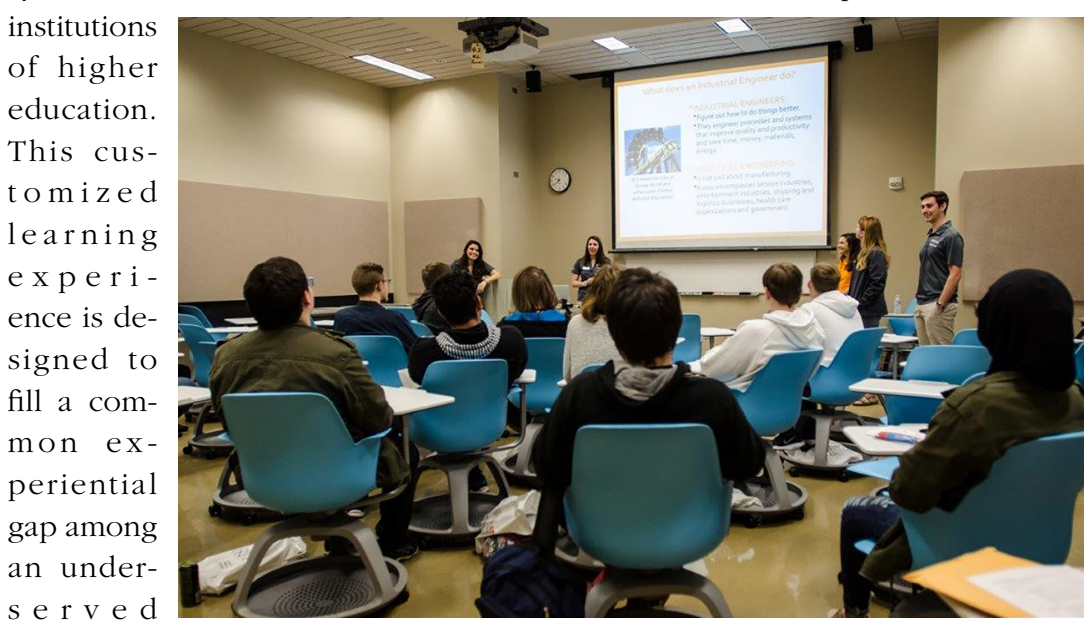

$\mathrm{s}$ e r v e d

p o p u l a - Students engaged in a workshop presented by students from the Unition that versity of Tennessee's Tickle College of Engineering.

is likely to

include many first-generation college students. It is important to create an enjoyable experience for the students and to convince them that STEM can be fun.

It has been noted that "using library spaces to design and facilitate conferences for high school students changes traditional mindsets about how libraries can promote college preparedness." ${ }^{4}$ Showcasing the academic library and its integral role in scholarship demonstrates the library's dedication to student success and college preparation. UT's BOSS program "presents educational and career opportunities in the STEM areas and aims at UT and universities in general. to prepare pre-college students for higher education classroom experiences."

\section{Gathering feedback}

Having access to information about participants' experience in outreach endeavors such as BOSS is essential to the program's longevity and success. For the past eight years, the responses of students participating in BOSS have confirmed that hands-on learning is their preferred method of engagement as opposed to a textbook or lecture approach. Studies indicate that exposing youth to STEM through hands-on activities teaches young people the art of problem-solving and the value of perseverance. ${ }^{6}$ Using hands-on

learning $\mathrm{m}$ a $\mathrm{k}$ e $\mathrm{s}$ STEM edu c a t i o n more attractive to students. Every student introduced to STEM at these conferences is allowed to explore options they never th o u g h t possible. According to the most recent data from the 2018 BOSS Conference, 95 percent of students agreed that following the conference they had a better understanding of STEM education, college preparation, and career options

At the end of the 2018 conference, surveys were administered to students electronically using data collection tools that were already familiar to many of the participating students through previous interactions with the Outreach Center. The survey instrument used to gather the data included a combination of short answers, Likert, and multiple-choice questions. The UT Libraries used NVivo 
qualitative data analysis software to analyze the surveys. By using qualitative coding in NVivo, librarians were able to examine the feedback more thoroughly, to see correlations between questions, and to verify assumptions that informed the conference design.

When assessment surveys were administered to conference participants, the most frequent reason for attendance selected was participation in the CAPS program. This is to be expected, given that the UT Libraries' primary conference partner is the CAPS program, and one of the major goals of the event is to expose underserved student populations to poten-

tial college majors and careers that they might not consider ot h e r wise. The results showed $\mathrm{w} \mathrm{hi} \mathrm{ch}$ specific S T E M programs students preferred,

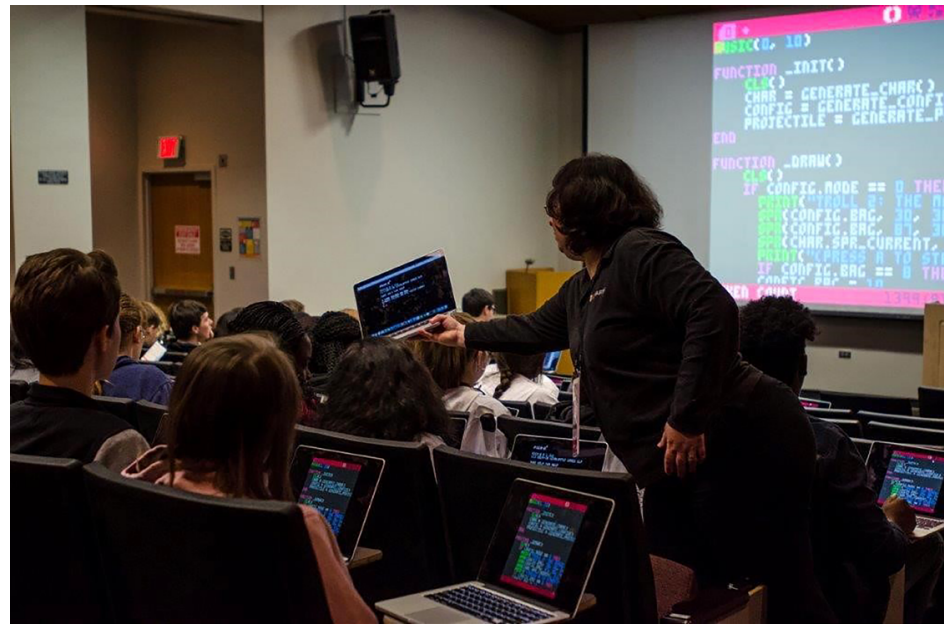

derstand more aspects of career planning (32 respondents). Based on the overall response to this question, librarians can demonstrate that BOSS has a positive effect on the students who attend.

Making teachers aware of the feedback received from the students during these conferences would allow the teachers to implement these findings in the high school curriculum, and prompts the question, "What more could teachers do for students in the classroom?" Giving the teachers evidence of the conference findings will be justification for them to consider building a more robust curriculum to reflect these findings. This w o u $1 \mathrm{~d}$ create an effective learning literacy cycle: the students make new discoveries, the discoveries are analyzed and coded, and the findand the general division of popularity supported interest in engineering compared to the popularity of other programs.

Data analysis also revealed that 100 percent of students indicated they did understand STEM better when asked, "Did you have a better understanding of STEM following the conference?" This particular question is important because it can help gauge the quality of the event and the sessions. It also demonstrates an interest in STEM from all students who attended. A majority of participants indicated that the event increased their STEM knowledge (40 respondents out of 84), gave them a better overall understanding of STEM (35 respondents), and helped them un- ings are then shared with teachers and school administrators.

\section{Conclusion}

Conference models such as BOSS grant students a voice and allow them to become part of the conversation about their futures in STEM. Feedback from the UT Libraries' 2019 STEM conference, for example, suggested that elements of STEM literacy might be productively incorporated into high school curricula. Surveys of student participants are key to receiving vital feedback that documents an outreach program's strengths and weaknesses. With these findings, it is possible to imple-

(continues on page 450) 
ship Study Grant (sponsored by the Walter de Gruyter Foundation for Scholarship and Research): $€ 2,500$ grant. Supports research in European studies with an emphasis on librarianship, the book trade, resource documentation, and similar information-science related topics.

\section{Publications}

- Katharine Kyes Leab and Daniel J. Leab Exhibition Catalogue Awards (sponsored by Katharine Kyes Leab and Daniel J. Leab, American Book Prices Current): recognizes outstanding catalogs published by American or Canadian institutions in conjunction with library exhibitions. Deadline: October 15, 2019.

- Ilene F. Rockman Instruction Publication of the Year Award: (sponsored by
Carrick Enterprises): \$1,000 award. Recognizes an outstanding publication related to instruction in a library environment published in the last two years.

- Science and Technology Section Oberly Award for Bibliography in the Agricultural or Natural Sciences: This biennial award is given in odd-numbered years for the best English-language bibliography in the field of agriculture or a related science.

For more information about the ACRL Awards Program, visit the Awards \& Scholarships section of our website at www.ala.org/ acrl/ or contact ACRL Program Officer Chase Ollis at collis@ala.org.

We welcome your nominations and look forward to celebrating achievements in academic librarianship in 2020. $\boldsymbol{z}$

("Assessment and social change," continues from page 437)

ment new ideas and create social change in the futures of underserved students.

Looking forward to 2020 and beyond, the BOSS initiative will take a radical step with the creation of BOSS in a Box, a portable STEM literacy tool.

An extension of the BOSS program, BOSS in a Box will enable BOSs to continue to branch out and impact the college and career options for students. It will provide a way to more directly influence students and teachers with a visual learning package that sets out to create experiential learning for students pursuing STEM majors and careers. It will help students achieve customized learning experiences through a multitude of available programs and expansive options to enable them to move forward after the initial lesson.

In the future, it is our hope that BOSS will continue to grow and implement new concepts to increase students' interest in STEM.

\section{Notes}

1. Lisa M. Frehill, Nicole M. Di Fabio, and
Susan T. Hill, "Confronting the 'New' American Dilemma-Underrepresented Minorities in Engineering: A Data-Based Look at Diversity," National Action Council for Minorities in Engineering, 2008.

2. Tsui Lisa, "Effective Strategies to Increase Diversity in STEM Fields: A Review of the Research Literature," Journal of Negro Education 76, no. 4 (2007).

3. Christopher Ball et al., "Invaluable Values: An Expectancy-Value Theory Analysis of Youth's Academic Motivations and Intentions," Information, Communication, \& Society 19, no. 5 (2016).

4. Kenya Flash et al., "Stem Bridges: Evolution of an Academic Library Stem Outreach Program," Journal of Library Administration 57, no. 8 (2017).

5. Ibid.

6. Tracey A. Overbey, Daniel S. Dotson, and Molly Myers LaBadie, "Public Libraries and Higher Education Combining Efforts to Create Quality Stem Children's Programs," Public Library Quarterly 37, no. 1 (2018). . 